\title{
An MFDFA Study to find Herd Behaviour and Information Asymmetry during Demonetization
}

Niranjana Balasubramanian*

\begin{abstract}
The paper attempts to identify how the Indian stock market reacts to an unusual event like demonetization through the observation of herd behavior. The data set considered is the NIFTY 50 index collected on $9^{\text {th }}$ November 2016. This method could become a failure if giant investors are well aware of the massive proceeding as stock markets are prone to information asymmetry. Thus, the existence of the same is checked using Hill estimator. The sectoral herding behavior is also captured for three selective sectors namely PSU banks, Energy sector, and Automobile sector as each sector may pose a different response towards the event. The volatility index is examined for a time period of 10 years from 2008 to 2018.
\end{abstract}

Keywords: Demonetization, Herd Behaviour, Information Contagion, NIFTY 50

\section{Introduction}

The herd effect, most prevalent in the financial market occurs when investors blindly follow other investors and thus neglecting the information that they have. The genesis of this scenario is identified to be an uncontrollable state, adopted by all of the investors, thus causing collective hysteria. This is famously called as a panic state. Some studies say that this is

* Tata Consultancy Services, India; niru1595@gmail.com 
an intraday phenomenon because people follow or imitate others when they have less time to make a decision. This is called information cascading in behavioural finance which is very similar to herd behaviour.

A lack of decision-making capability or introspection leads to the herd instinct. This makes them follow what they perceive other investors are performing (buy or sell). They often end up doing this because of a fear of missing out on a profitable investment opportunity. It is identified that information asymmetry leads to herd behaviour and thus herd behaviour ends up in creating a bubble in the market when there is a shock. A shock can be either positive or negative. All constructive information is assumed to be positive and all gloomy information is negative. Events like Tulip mania in 2008 created a crisis that created a shock amongst investors and thus they end up in herding.

Efficient Market Hypothesis (EMH) says two important factors: information and time. It presumes that all investors have access to complete information on time. But this does not exist in the real market and thus comes information asymmetry. Since people do not have access to the right information, they just follow other investors creating a herding effect in the market. This leads to a price hike or drop causing the value of the asset to be higher or lower than its intrinsic value. If this persists in the market, this creates a positive or negative bubble.

This creates an impulsive buy or sell behaviour amongst the investors and weakens the process of fair price-discovery which will have a detrimental effect on the market. This can affect the financial position of the country and thus creating a downside in the economy. This study aims to understand the herding behaviour amongst investors during a blow-up situation in India: Demonetization. 
On the $8^{\text {th }}$ of November 2016, the Modi government announced the demonetization for the third time in the country post-independence. 500-rupee notes and 1000-rupee notes were demonetized, and at the same time issuance of new 500 and 200-rupee notes was announced. This move was initiated to curtail terrorism and shadow economy and also to overcome counterfeit cash. This created a trauma state among the citizens and thus affected all the sectors including the stock market. It created a fear in the investors. This could lead to a herd behaviour or formation of a bubble in the market.

Since demonetization was announced post the closure of the stock market, its effect in the stock market could be observed only the next day. Hurst exponent gives a significant measure of herding and thus high-frequency data for three hours (9 AM to 12 PM) on 09th November 2016 is traced for herding or bubble behaviour.

Another related component added to the study is the Volatility Index (VIX). It is a real time market index that tells about the future expectation of volatility in the market. As Indian VIX is also derived from the NIFTY index, its data can be used to identify the market risk and investors' sentiment. This index is also famously known as the fear index or fear gauge.

A mathematical construct based on behavioural finance named herding is being studied during demonetization. An event, not sporadic will have a shock in all the industry and thus affecting the stock market which includes equity, commodities and so on. Thus, during those periods there can be a possibility of herd behaviour amongst investors and forming a base for a bubble. The mindset of the participants in the stock market can be understood by using Hurst exponent.

The value lies between 0 to 1 . It is found that predictability is higher for a time series that has a high Hurst exponent. 
Similarly, a time series with higher Hurst exponent means that it follows a pattern and this pattern occurs because of the herding behaviour by the market participants. Similarly, the level of information that one receives is different from other as stated by the efficient market hypothesis. According to Standard and Poor's survey in 2015, India has just $24 \%$ of the financial literacy rate which is way below the average. Even if two investors have access to the same level of information, it is being perceived in two different forms. Investors decipher the information that they have according to their behaviour, background, their needs and requirements thus leading to information asymmetry. Information asymmetry can be identified using the Hill estimator. This is used to identify the presence of heavy tails which are called extremes. A positive extreme is supposed to happen when an investor receives an abnormal gain and negative extreme happens when an investor ends up in huge losses.

Similar to information asymmetry, there exists something called information uncertainty. Entropy is a measure of information asymmetry; thus, we use Shannon's entropy to measure the level of uncertainty. If the value is less than 3.5 then the information uncertainty of dataset processed is within control. But if the value is greater than 3.5, then it means that the information uncertainty is beyond control and crisis is on the horizon.

This study focuses on analysing the results obtained by calculating the Hurst exponent to find herding behaviour in the market. It also finds the Hill Estimator to predict if there exists an information asymmetry.

This work can be exclusively used by market participants who wish to make buy or sell decisions in an Indian market during an astronomical event like demonetization. This could also be used by an analyst to understand how markets react as a whole. It can also be identified if all sectors react the 
same way or few sectors react positively and few sectors react negatively.

This is the first attempt that tries to connect herding, information asymmetry, information uncertainty, and market bubble during demonetization.

\section{Literature Review}

Four Indian researchers Ghosh, Krishna, Rao, Kozarević, \& Pandey (2018) have identified the herd behavior and predictability using CNX Nifty regular and high frequency time series. They have selected their time series for threeyears from 2013 to 2016. They identified evidence of predictability and herd behavior in both CNX regular and high frequency data. They also proved that the predictability of HFT data is more than the normal time series. The data strongly proves that an event of crisis brings the herd mentality in the stock market.

A unique identification of financial Reynolds number has been produced by the authors Ghosh \& Kozarevic (2018) which can be strongly used as a proxy for volatility in the market. It can be used as an indicator that tells the investors the right time to exit the market. This can be reliable even in case of a black-swan event. It has been identified that lower the financial Reynolds number, lesser the volatility in the market and similarly if the value tends to be more than 10, it is highly recommended to exit the market. The authors suggest that the model is so strong that it can even be used by policymakers to caution the investors.

It has been identified by Ghosh \& Krishna (2019) that the risk and return of various stocks and commodities follow inverse cubic law as the tail exponent is found to be close to 3 which is much higher than the Levy regime $(0<a<2)$. This has been concluded using data set with 3918 observations from January 2001 to December 2016 using the Hill Estimator along 
with the financial Reynolds number that was taken tick by tick from 2012 to 2016. The observation proves that the power law pattern is true and also it is inverse in both the case of risk as well as return. As discussed in the previous paper, the financial Reynolds number has been used as the risk parameter. This finding holds even in case of the extreme risk and return combinations.

The authors Cipriani \& Guarino (2008) emphasize more on the information cascading which happens when there is a blockage of information into the market and the price of the asset will vary far from their original prices. This forms the base for herding behaviour among investors. Information cascading also leads all the investors to choose the same decision or go against it. They also identified that a spillover effect takes place where the assets are correlated more than the extent they actually should be.

This paper is a reconciliation of opposing findings by The \& May (2006) on returns of financial securities and option pricing. The model obeys power law damped by an exponential function. The model is flexible enough which takes both positive and negative damping along with different prices which are upside or downside.

The author identifies that if there is an information contagion, there is a higher possibility that even the profit-making banks will have a herding behavior and follow what other similar banks do, as said by Journal \& Feb (2018). This has been linked with the borrowing rates of the bank. If two banks have higher returns then they borrow at lower rates, if one bank has a higher return and the other has lower return the negative spillover of bank $B$ will affect the borrowing rate of bank A. Finally, if both banks have lower returns, then they borrow at high rates.

This paper deals with the identification of long memory in various fields like climate, hydrology, finance, network, and 
DNA sequencing. The authors Graves, Gramacy, Watkins, \& Franzke (2017) feel this is important because if it is known that a process has long memory or not, the level of accuracy in predicting future events with historical data can be higher.

The author Ghorbel, Boujelbene, \& Boujelbene (2014) confirms the presence of contagion effect in Asian markets during the crisis period. The correlation coefficient between the country's stock prices gives rise to evidence of the contagion effect. This was further proved by applying the vector error correction model. This can also be used for understanding herd behavior that is prevailing in the market. By analyzing the impulse response function (Mandelbrot, 1970) which tends to change when there is a crisis can be used as a factor to analyze herding behavior in the market. Similarly, innovation accounting can also be used.

Similar work is done by Caporale, Cipollini, Spagnolo, Economics, \& Mary (2002) where he proves that contagion exists especially in the East Asian region by using a parameter stability test which majorly rectifies three biases namely heteroscedasticity, endogeneity and omitted variable. The heteroscedasticity bias is rectified through a GARCH process. The test was restricted to eight Asian countries namely Indonesia, South Korea, Malaysia, Taiwan, Singapore, Hong Kong, the Philippines, and Thailand. It was strongly proved that the spill-over effect persisted and evidence of contagion was found in almost all countries except IndonesiaMalaysia and Singapore-Malaysia.

Empirical evidence of behavioral contagion has been established by the author Ghorbel et al. (2014) between stock prices of oil importing and oil exporting countries which are around 22 countries with the US market. Three variables namely oil returns; US markets and stock prices of those 22 countries were used to analyze the spillover effect through BEKK-GARCH model. A steep increase in the correlation 
coefficient of the oil market and the stock market was experienced during the financial crisis period 2008-2009 which thus proved that herding contagion existed during the turmoil period (Hurst, 1978). The herding bias and investor sentiment have been used as a key variable to explain the volatility. The adjusted range has been given by William (2012).

A research team of A. Kumar, Bharti, \& Bansal (2016) studied the presence of herding in the Indian market during the period 2008 to 2015 . They employed a cross-sectional absolute deviation to test the herding behaviour. It was surprisingly found that there was no trace of herding in the market. They followed Chang model according to which a negative nonlinear coefficient indicates the existence of herding and positive non-linear coefficient indicates no herding. It was found that the absence of herding was due to the poor participation of retail investors in the stock market and a large percentage is handled by the institutional investors who make informed decisions.

A sectoral wise investigation on herding was carried out by BenSaïda (2017) through a modified cross-sectional absolute deviation model. The modification attempted to include trading volume and investor's sentiment into the model. It was found that if there is information asymmetry in the market, people who tend to have more information take privilege out of it and perform large volume transactions which lead to volatility in that particular stock price. The descriptive statistics showed a positive value for volume turnover and sentiment index and thus proving the presence of herding. Thus, out of the 12 sectors chosen, 10 showed positive results for herding, and it was also found that volume turnover does not cause herding in any circumstances. 
The authors, Dungey \& Tambakis (2003) found an interesting connection between financial contagion and market crisis and they specifically said that the contagion effect arises in the crisis period. They also found that literal contagion has an association with herding but the reverse might not hold. They quoted that though the policymakers wish to reduce the extreme movements in the market, they give more importance to the negative fall by the introduction of electronic program driven stops in the equity market.

An examination of how a shock in the Mexican market can have a spillover effect on Asian and Latin American countries was showed by Frankel \& Schmukler (2005). It was found that the co-movements among East Asia, Latin America, and New York was high, the Mexican shock in 1994 seems to have a stronger impact on weak countries. The vulnerability also changed based on the country's debt/export ratio: having a direct proportion. Different combination of Granger test was conducted to find how past changes in the country fund NAV and prices could affect the present value.

The authors Parker \& Prechter (2012) introduced us to different concepts of herding namely: social psychological approaches, ethological and biological approaches, information theory and cybernetic approaches, medical model approaches, econophysics approaches, and the socionomic model. The author also highlighted the two schools of thoughts on human behaviour, the former believes that human has herd instinct and the latter believes that man reacts rationally based on the given situations.

A group of researchers Ghorbel et al. (2014) worked on developing an agent based multinational model that investigates the reasons for contagion. An intelligence technique was followed that would detect the contagion at an early stage and thus prevent massive destruction in the market and thus destabilising the cross-market linkages. This 
method would be extremely important in the creation of risk management strategies. They also focused on finding out how contagion occurs among the linked financial markets.

An attempt by S. S. S. Kumar, (n.d.) was made to understand the behaviour of institutional investors on the stock market before and after demonetization. Demonetization was introduced to control corruption, black money, and terrorism in the country. The change in the behaviour is being observed by looking at Gross Sales and Gross Purchases by Foreign Institutional Investors (FIIs) and Domestic Institutional Investors (DIIs). It was discovered that in the pre demonetization period there was a positive impact on the buying behaviour and negative impact on selling behaviour. This trend continued to exist post demonetization; thus, it was concluded that demonetization did not impact the institutional investors.

The post effect of demonetization on the retail sector was captured by Rani (2016) and also, how people started shifting to digital payments because of the cash crunch. The buying behaviour of consumers was observed. It was found that even the top brands got a hit in their sales because of demonetization. It was noted that the credit span that was given to the customers was extended as they were unable to pay the cash immediately whereas on the other side the wholesalers denied to extend the credit span to the shopkeepers. The author says that though the initial stages of demonetization were painful, this paved the way for digital payments like Paytm, Debit/Credit card transactions.

As the banking sector was the one that was most affected by demonetization, the authors Issn \& Neralla (2018) have tried to analyse the impact of it on the banking sector especially loans and advances. This is the sector through which the money circulation happens in the entire economy and if this gets a hit, certainly it would affect all other sectors. But this 
hectic situation gave openings for digital payments, ebanking, and e-wallet. T-test was used to determine if demonetization had an impact on loans and advances of SBI. The null hypothesis was accepted as the calculated value was less than the critical value proving that demonetization did not have any impact on the banking sectors specifically to loans and advances.

As it was observed that demonetization paved the way for digital banking, the author Ahmad (2017) tried to understand the impact of online banking transaction post demonetization. The data has been collected for 100 days; 50 days before and 50 days after demonetization. Correlation analysis was carried out between money circulation and selected online bank transactions (NEFT, RTGS, IMPS, POS, NACH) and it was observed that there was a negative relationship between them. Also, the Granger casualty test was applied and was found that there was a significant increase in the volume of online transactions that happened post demonetization. It was also found that post demonetization, there was a negative influence by money circulation on IMPS and POS.

In this paper, he presented the fundamental framework of the evaluation problem under which the evaluation operator satisfying some axioms is linear. Based on the dynamic linear evaluation mechanism of contingent claims, studying this evaluation rule in the market driven by fractional Brownian motions has led to a dynamic capital asset pricing model. It is deduced here mainly with the fractional Girsanov theorem and the Clark-Haussmann-Ocone theorem.

The authors Hindocha \& Pandya (2019) tried to understand if demonetization had an effect on electronic mode of transactions especially on National Electronic Fund Transfer (NEFT) and Real-Time Gross Settlement (RTGS). The changes were measured in terms of volume and value of transactions performed. Along with this, the increase in the number of 
mobile banking transactions was noted. A sampling technique called purposive sampling was used and it was found that all three: NEFT, RTGS, and mobile banking had a significant increase in both the volume and value of transactions.

Demonetization did not only affect different sectors; it also affected the employees of various sectors especially the banking sector. They were asked to work overtime to control the crowd and they were pressurized to bring in and adapt to the change as early as possible. The authors Gupta \& Agarwal (2018) said that this made the stress level higher for them in a short span. This has been observed through PE-fit theory, cybernetic theory, and control theory. This study proved that there was a significant impact on the stress levels of nationalized banking employees immediately after demonetization.

\section{Methodology}

The objective of the study are as follows:

1. To trace the possibility of herd behaviour amongst investors (NIFTY 50) during demonetization using Hurst exponent in MFDFA.

2. Sectoral evidence of herd behaviour.

3. To check if there is information asymmetry using the Hill estimator.

4. Volatility identification using India Volatility Index (VIX) dataset.

The high frequency NIFTY 50 data for the year 2016 was purchased by MRPDCM in the year 2016 from NSE DotEx. It is a company called NSE Data \& Analytics, a subsidiary of NSE which provides data products for online streaming tick by tick data, snapshot data feed, end of day data, historical 
data, and corporate data. It acts as an info base which provides daily information updated and complete.

The VIX data has been taken from Yahoo Finance. It provides financial news and financial data. It also provides tools for personal finance management.

All the above listed data are open source and highly credible and thus making it a reliable source for the study.

The dataset contains NIFTY high frequency data for three hours from $9 \mathrm{AM}$ to $12 \mathrm{PM}$ on the next day of demonetization, 09-11-2016. High frequency data refers to time series data collected for an extremely smaller duration (tick by tick). It is used in financial analysis especially when an intra-day observation is made. It is helpful in understanding the market dynamics, its behaviour and even micro information. Along with this, the Volatility Index, derived from NIFTY is also taken into observation for a period of 11 years starting from 2008 to 2019. NIFTY high frequency data includes 8000 data points and VIX includes 2738 data points.

\subsection{Steps in the methodology}

STEP 1: NIFTY 50 data was collected on the next day of demonetization, 09-11-2016 using high frequency data for three hours from 9 AM to 12 PM consisting of 8000 odd data points.

STEP 2: This dataset is given as an input in MATLAB using MFDFA. The original data is used as multifractal, Lag 1 is considered as monofractal and Lag 2 is considered as white noise.

STEP 3: The output is verified to understand if the dataset has herding or a bubble behaviour in it.

STEP 4: Parallelly, Indian VIX is taken for 11 years from 2008 to 2019. 
STEP 5: Its volatility is understood by finding its Hurst exponent by splitting the entire data into 5 different data sets.

\section{Result and Discussion}

The original time series containing 8000 datasets are taken as multifractal data. Lag 1 of the same dataset is considered as monofractal and Lag 2 is considered as white noise. The values are then imported into MATLAB from MS Excel. MFDFA is a plugin used in MATLAB which is used to detect the value of the Hurst exponent. Once data is imported the MATLAB code is run. It generates around 16 figures which are used for different purposes. In this case Figure 8 is considered for the multifractal spectrum, Figure 12 is considered for $\mathrm{Hq}(5)$, and Figure 15 is considered for time dependent $\mathrm{H}$.

\subsection{Hurst Exponent and its Interpretation}

Table 1: Hurst Exponent and its Interpretation

\begin{tabular}{cl}
\hline Hurst Exponent & \multicolumn{1}{c}{ Interpretation } \\
\hline $0<\mathrm{H}<0.5$ & Non-persistent, no herding, \\
& no bubble, no pattern, data is \\
& fractal, risk component is \\
& high, and surface is rough. \\
& No predictability, random \\
& walk, and completely \\
& stochastic. \\
& Clear pattern, persistent, data \\
& is fractal, traces of herding, \\
& black noise, and risk \\
& component is high here as \\
& well.
\end{tabular}


Using the Hurst exponent it was found that, Fractal dimension can be calculated. Fractal dimension corresponds to Hurst exponent, and is calculated by

Fractal Dimension = 2- Hurst Exponent

Interpretation of Hurst Exponent

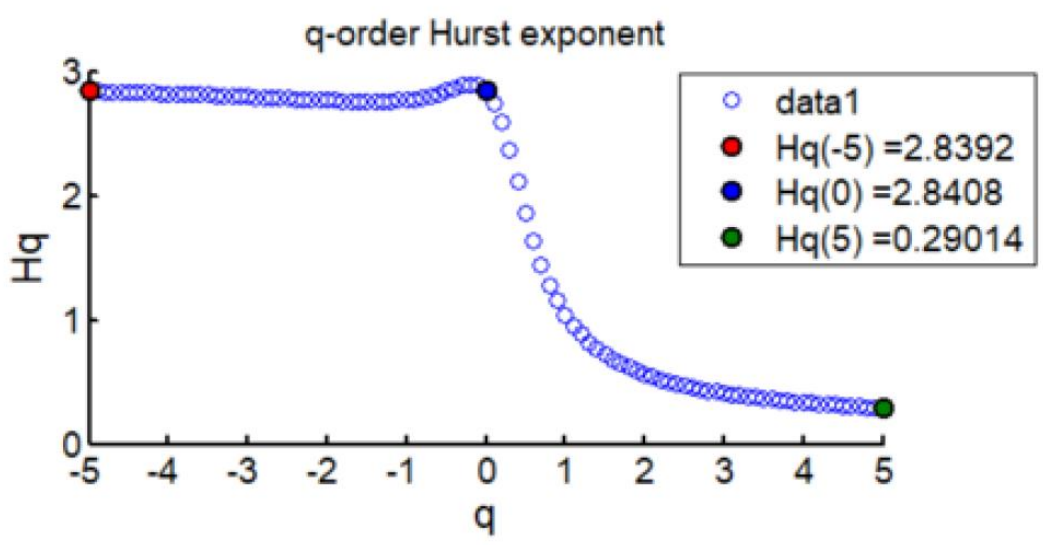

Figure 1: Interpretation of Hurst Exponent

\subsection{Measures for quantifying herding}

Table 2: Measures of quantifying herding

\begin{tabular}{ll}
\hline Hurst Exponent & 0.29014 \\
Fractal Dimension & 1.70986 \\
Hausdorff Topology \\
(Pinwheel Fractal)
\end{tabular}




\subsection{Hill Estimator Results}

Table 3: Hill Estimator Results

\begin{tabular}{ll}
\hline Total data points & 8074 \\
\hline No. of Data packets & 97 \\
No. of Data points & 84 \\
in each packet & \\
Iota & 9.473 \\
k & 3 \\
Alpha & 3.157 \\
\hline
\end{tabular}

Shocking evidence of herding has been brought out through the process of MFDFA. India, having a very poor financial literacy rate of $24 \%$, lesser than the average rate of south Asian countries. But the Hurst exponent shows a value of 0.29 which proves that there is no herding or bubble (Ghosh \& Kozarevic, 2019) in the market during demonetization. Also, the alpha value is 3.157 proving the market to be inefficient. It means that the prices are random and not influenced and not affected by past events. This phenomenon is also shown by the Hausdorff Topology which gives a figure of Pinwheel fractal for a fractal value of 1.7. The pictorial representation is used to make heuristics for an average investor. Thus, just by looking at the figures they can judge if it is time to buy, sell or hold the stocks.

\section{Conclusion}

The study attempted to find how markets react during a catastrophic event. The scenario taken was demonetization which has happened only thrice in Indian market postindependence. It is a big step taken to curb black money, stop unaccounted transactions and bring all the money into the circulation. Once demonetization came into effect, there was a huge crunch for cash and affected almost everybody in the country. There were restrictions in the withdrawal of amounts in ATMs and most of the banks ran out of cash, 
making people wait in queues for a longer duration. This event also affected business and few small-scale industries had to shut down their business temporarily. Considering all of these circumstances, the study was undertaken to find if this event even affected the stock market. A simple way to understand if an event has affected the stock market is to find if there is too much buying or selling in the market. If there are enough buying and selling in the market, then this would create a bubble in the market, leading to a herd behaviour amongst investors. Thus, finding out the Hurst exponent on the next day of demonetization would let us know if there was a sudden shock amongst the investors. The value surprisingly turned out to be 0.29 which is way less than 0.5 (Ihlen, 2012) proving that there is no trace of herd or bubble in the market. To confirm this, the Volatility Index (VIX) was also checked for herding and it showed a result of 0.41 . This proves that there was not much fluctuation in the market on that date. A country having a very low financial literacy rate shows that it does have strong herding even on a day when the entire country is under stress.

Talking about the sectoral herding, three sectors were taken into consideration: PSU banks, Energy Sector, and Automobile industry. PSU banks had a good response for demonetization as they expected a lot of money to pool in which would increase their CASA Ratio. The energy sector which includes power, oil and gas expected a positive response as this sector was accepting older cash to pay their bills and which would highly reduce their dues. The automobile industry was hardly hit by demonetization. This sector highly dealt with cash and thus had a negative impact towards demonetization since there were restrictions in the amount that could be withdrawn in a day and thereby hitting the sales of hatchback, sedan, and SUV models. 


\section{References}

Acharya, V. V., \& Yorulmazer, T. (2008). Information contagion and bank herding. Journal of money, credit and Banking, 40(1), 215-231. Ahmad, S. (2017). Demonetization - Its Impact on Banking Online Transactions. Sumedha Journal of Management, 6(3), 4-15.

BenSaïda, A. (2017). Herding effect on idiosyncratic volatility in U.S. industries. Finance Research Letters, 23(November), 121-132. Caporale, G. M., Cipollini, A., Spagnolo, N., Economics, F., \& Mary, Q. (2002). Testing for contagion. International Journal of Applied Research, 44(0), 0-14.

Cipriani, M., \& Guarino, A. (2008). Herd behavior and contagion in financial markets. The B. E. Journal of Theoretical Economics Contributions, 8(1), 34-37.

Dungey, M., \& Tambakis, D. (2003). International Financial Contagion: What Do We Know ? Working Paper, (9).

Feller, W. (1951). The asymptotic distribution of the range of sums of independent random variables. The Annals of Mathematical Statistics, 427-432

Frankel, J. A., \& Schmukler, S. L. (2005). Crisis, Contagion, and Country Funds: Effects on East Asia and Latin America. SSRN Electronic Journal, 23(3-4), 36-71.

Ghorbel, A., Boujelbene, M. A., \& Boujelbene, Y. (2014). Behavioral explanation of contagion between oil and stock markets. International Journal of Energy Sector Management, 8(1), 121-144.

Ghosh, B., \& Kozarevic, E. (2018). Identifying explosive behavioral trace in the CNX nifty index: A quantum finance approach. Investment Management and Financial Innovations, 15(1), 208-223.

Ghosh, B., \& Kozarevic, E. (2019). Multifractal analysis of volatility for detection of herding and bubble: Evidence from CNX Nifty HFT. Investment Management and Financial Innovations, 16(3), 182-193.

Ghosh, B., \& Krishna, M. C. (2019). Power law in tails of bourse volatility - evidence from India. Investment Management and Financial Innovations, 16(1), 291-298.

Ghosh, B., Krishna, M. C., Rao, S., Kozarević, E., \& Pandey, R. K. (2018). Predictability and herding of bourse volatility: An econophysics analogue. Investment Management and Financial Innovations, 15(2), 317-326. 
Graves, T., Gramacy, R., Watkins, N., \& Franzke, C. (2017). A brief history of long memory: Hurst, Mandelbrot and the road to ARFIMA, 1951-1980. Entropy, 19(9).

Gupta, R., \& Agarwal, M. (2018). Work stress among Indian bank employees: Impact of demonetisation. 8(1), 95-99.

Hindocha, M., \& Pandya, J. K. (2019). The impact of demonetization on electronic fund transfers. Journal of Accounting an Financial Management, 17(1), 32-35.

Hurst, H. E. (1978). Harold edwin hurst. International Journal of Finance \& Banking Studies, 23(3), 335-336.

Ihlen, E. A. F. (2012). Introduction to multifractal detrended fluctuation analysis in Matlab. Frontiers in Physiology, 3, 1-18.

Kumar, A., Bharti, M., \& Bansal, S. (2016). An Examination of Herding Behavior in an Emerging Economy- A Study of Indian Stock Market. Global Journal of Management and Business Research, 16(5), 1-9.

Kumar, S. S. S. (2006). Role of institutional investors in Indian stock market. Investment Management and Financial Innovations, 16(2), 23-27.

Mandelbrot, B. B. (1970). Comment on 'Stochastic Models in Hydrology' by Adrian E. Scheidegger. Water Resources Research, 6(6), 1791-1791.

Neralla, N. (2018). Demonetisation Impact over Banking Loans \& Advances: A Case Study. International Journal of Finance $\mathcal{E}$ Banking Studies (2147-4486), 7(4), 51-64.

Parker, W. D., \& Prechter, R. R. (2012). Herding: An Interdisciplinary integrative review from a socionomic perspective. SSRN Electronic Journal.

Rani, G. (2016). Effects of demonetization on retails outlets. International Journal of Applied Research, 2(12), 400-401.

$\mathrm{Wu}, \mathrm{L}$. (2006). Dampened power law: reconciling the tail behavior of financial security returns. The Journal of Business, 79(3), 14451473. 